\title{
İstanbul Aktarlarında Satılan Bitkisel Çaylarda Ağır Metal Tayini
}

\author{
Dilek BİLGIÇ ALKAYA, Serap KARADERİ, Gülbin ERDOĞAN, Ayşen KURT CÜCÜ
}

\section{ÖZET}

Bitki çayları Türkiye'de oldukça fazla miktarda tüketilmektedir. Çaylar pek çok faydalarının yanı sıra yapılarında ağır metalleri de barındırırlar ve çevre kirliliği arttıkça çaylardaki ağır metal kirliliği de artmaktadır. Araştırmada adaçayı, biberiye, sarı kantaron, ıhlamur, nane, kekik, papatya, rezene, yeşil çay, yaban mersini kullanılmış ve kurşun ve kadmiyum metallerinin aktarlardan alınan çaylardaki konsantrasyonları atomik absorpsiyon spektrofotometresi ile incelenmiştir. Sonuçlar incelendiğinde çaylardaki kadmiyum ve kurşun konsantrasyonlarının sınırlar içinde olduğu bulunmuştur.

Anahtar kelimeler: Bitkisel çay, ağır metal, atomik absorpsiyon, kadmiyum, kurşun
Dilek Bilgiç Alkaya, Serap Karaderi, Gülbin Erdoğan, Ayșen Kurt Cücü

Marmara Üniversitesi Eczacllı Fakültesi Analitik Kimya ABD

Haydarpaşa İstanbul

\section{Sorumlu Yazar:}

DİLEK BİLGİÇ ALKAYA

Marmara Üniversitesi Eczacılık Fakültesi

Analitik Kimya ABD Haydarpaşa İstanbul.

Tel: $02164142962-1165$

Fax: 02163452952

E-mail: dbilgic@marmara.edu.tr

\section{GíRiş}

Bitkisel çaylar bitkilerin köklerinin, kök gövdelerinin, dal sürgünlerinin, yapraklarının, çiçeklerinin, kabuklarının, meyvelerinin veya tohumlarının aromatik kısımlarının kurutularak, kaynar suda içime uygun hale getirilerek hazırlanmasına dayanan karışımlardır. Bunun için kullanılacak drog çiçek ise tamamen açtıktan sonra, yaprak ise tek tek, ancak yaprakları dökülen bir bitki ise çiçeklenme döneminden önce, toprak üstü kısım bitkinin çiçeklenme döneminde, tohumlar ve meyveler olgunlaştıklarında, kökler ve gövdeler genellikle toprak üstü kısmın kuruduğu sonbaharda toplanmalıdır. Toplanmış olan bitkinin gerekli kısımlarının tıbbi olarak kullanılabilmesi için, o bitkinin öncelikle kurutulması gereklidir $(1,2)$.

Bugüne kadar önemli miktarlarda tüketilen bitki çaylarının inorganik madde içerikleri, mutajenik etkileri, mikrobiyolojik kaliteleri, kül-nem miktar tayinleri ile ilgili yapılmış birçok yurtiçi ve yurtdışı araştırma mevcuttur(3-5). Bitki çaylarını ağır metal içerikleri açısından değerlendiren çalışmalara bakıldığında ise bitkisel çayların kapsamında $\mathrm{Cu}, \mathrm{Co}, \mathrm{Zn}, \mathrm{Mn}, \mathrm{Fe}$ gibi bitkiler içinde doğal olarak bulunan ve insan sağlığı için gerekli olan metallerin yanı sıra $\mathrm{Ni}, \mathrm{Pb}$, $\mathrm{Cd}$, As, Hg gibi belirli seviyelere ulaştıklarında zehir etkisi gösteren bazı metallerin de bulunduğu görülmektedir (6-9). 
$\mathrm{Bu}$ durumun insan sağlığı açısından ciddi sorunlara sebep olduğu bilinmektedir. Bu nedenle son yıllarda çevre kirliliğ sebebiyle de gıdalara bulaşan toksik metaller, tüketici açısından sağlık sorunları oluşturduğu için halk sağlığ kurumları bu konuda çalışmalar yapmaktadırlar. Gıda Tarım Örgütü (FAO) ve Dünya Sağlı Örgütü (WHO) günümüz üretim şartlarını da göz önünde bulundurarak çeşitli gıdaların içerebileceği maksimum toksik metal miktarlarını belirlemiştir.

Suda çözünme özelliği en yüksek olan kadmiyum biyolojik fonksiyonlar açısından gerekli bir element değildir ve diğer ağır metallere göre 2-20 kat daha fazla toksik etkiye sahiptir. Suda çözünebilir özelliğinde dolayı Cd(II) iyonu halinde bitki ve deniz canlıları tarafından biyolojik sistemlere alınır. Bitki bünyesinde 1.0ppm' den fazla kadmiyumun bitkiler için toksik etkili olduğu ve 3 ppm' den fazla kadmiyum içeren bitkileri düzenli olarak tüketen insanlarda zehir etkisi yaptığ 1 belirtilmekle birlikte 6.15 $\mu \mathrm{g} / \mathrm{g}$ düzeyindeki kadmiyum birikiminin insan sağl 1 ğ 1 açısından önemli zararlara yol açabileceği saptanmıştır $(10,11)$.

Kurşunun vücutta $\% 5$ oranında olan absorpsiyonu kalsiyum ve demir gibi birçok mineralin vücut tarafindan emilimini azaltmaktadır. İyonik çap ve yük benzerlikleri nedeniyle, kurşun kalsiyumun yerine geçebilmekte ve kemik dokusuna yerleşebilmektedir. Yüksek miktarlarda kalsiyum alındığında kemik dokusuna yerleşip bağlanmış olan kurşun kalsiyumla yer değiştirebilmektedir. Böylece sistemde serbest kalan kurşun nefrotoksisite, nörotoksisite ve hipertansiyona neden olabilmektedir $(12,13)$. Bu çalışmada; yaygın olarak tüketilen bitkisel çayların (adaçayı, biberiye, ihlamur, kantaron, kekik, nane, papatya, rezene, yaban mersini ve yeşil çay) kadmiyum ve kurşun içerikleri üzerine aktarlardan alınan örnekler üzerinden incelemeleri yapılmıştır.

\section{GEREÇ VE YÖNTEM}

İstanbul'daki farklı aktarlardan temin edilen Thymusvulgaris L, Salviafruticosa L., Rosmarinusofficinalis L., Foeniculumvulgare L., Hypericumperforatum, Tiliacordata, (Vacciniummyrtillus, Menthapiperita L., Matricariachamomilla, Cameliasinensis bitkilerindeki ağır metal analizleri bitkilerin yaprak ve meyvelerinde yapılmıştır. Çalışmaya başlamadan önce $105{ }^{\circ} \mathrm{C}$ 'lik etüvde 48 saat kurutulmuş ve etüvden alınan numuneler desikatörde bekletilmiştir. Kurutulmuş bitkilerden SCALTEK SBA 31 elektronik terazi kullanılarak 3 er tartım alınmıştır (Tablo 1). Tartılan numunelerin IKA LABORTECHNIC RH BASIC İKASMAG RET-GS Hot Plate ile yaş yakma yöntemi ve
Tablo 1: Satın alınan çay örneklerine ait tartım sonuçları

\begin{tabular}{llcc}
\hline Alınan madde & Latince adı & $\begin{array}{c}\text { Miktarı (g) } \\
\text { Açık }\end{array}$ & $\begin{array}{c}\text { Miktarı (g) } \\
\text { Paket }\end{array}$ \\
\hline Kekik & Thymusvulgaris L & 0,2647 & 0,2609 \\
Adaçayı & Salviafruticosa L & 0,2746 & 0,2628 \\
Biberiye & Rosmarinusofficinalis L & 0,2441 & 0,2796 \\
Rezene & Foeniculumvulgare L. & 0,2506 & 0,2360 \\
Sarı kantaron & Hypericumperforatum & 0,2783 & 0,2657 \\
Ihlamur & Tiliacordata & 0,2334 & 0,2968 \\
Yaban mersini & (Vacciniummyrtillus & 0,2655 & 0,2954 \\
Nane & Menthapiperita L. & 0,3014 & 0,3121 \\
Papatya & Matricariachamomilla & 0,2729 & 0,2777 \\
Yeşil çay & Cameliasinensis & 0,2525 & 0,2820 \\
\hline
\end{tabular}

BERGHOFF marka mikrodalga parçalama sistemi kullanılarak çözünürleştirilmeleri sağlanmıştır.

Yaş Yakma Yöntemi: Tartılan örnek 100,0mL lik behere konularak 4,0mL der $\mathrm{HNO}_{3}$ ve $1,0 \mathrm{~mL}$ der. $\mathrm{HClO}_{4}$ eklenerek kaynatılmıştır. Parçalanmış kalıntı ultra saf su ile çözülmüş ve 1 numaralı filtre kullanılarak süzülmüştür. Üzerine 2,0 $\mathrm{mL}$ der $\mathrm{HNO}_{3}$ eklenmiş ve son hacim ultra saf su ile $100,0 \mathrm{~mL}$ ye tamamlanmıştır.

Mikrodalga Çözünürleştirme Yöntemi: Mikrodalga ünitesinde tartılan örnekler mikrodalganın teflon kabına alınmış ve teflon kaba $10,0 \mathrm{~mL}$ der. $\mathrm{HNO}_{3}$ eklenmiştir. Teflon kabın kapağı kapatılarak 20 dakika bekletilmiş ve mikrodalganın yakma ünitesine konulmuştur. Mikrodalga cihazından çıkan numuneler 50,0mL'lik plastik kaplara alınmıştır.

Numunelerdeki kurşun ve kadmiyum konsantrasyonlarını ölçmek için Schimadzu AA-6800 F, Japan FAAS cihazı, SCHIMADZU ASC6100 autosampler ve girişimleri engellemek için BGC-D2(Zeeman Background Correction Deuterium) kullanılmıştır. Atomlaşma ortamı olarak bu elementler için uygun olan hava asetilen alevi kullanılmıştır. Ölçümlerde kurşun için Hollow Cathode Lamp L-23382NQ Kurşun Katot Lamba ve kadmiyum için ise Hollow Katod Lamba L-233-48NQ Kadmiyum Katot Lamba kullanılmış ölçüm şartları aşağıdaki tabloda verilmiştir.

Tablo 2: Örnekler için belirlenen ölçüm şartları

\begin{tabular}{lcc}
\hline & Kadmiyum & Kurşun \\
\hline Dalga boyu(nm) & 228,8 & 283,3 \\
Slit genişliği(nm) & 1,0 & 1,0 \\
Işık kaynağı & Oyuk katot & Oyuk katot \\
Lamba akımı(mA) & $8 \mathrm{~mA}$ & $10 \mathrm{~mA}$ \\
Alev tipi & Hava- $\mathrm{C}_{2} \mathrm{H}_{2}(1,8 \mathrm{~L} / \mathrm{min})$ & Hava- $\mathrm{C}_{2} \mathrm{H}_{2}(2,0 \mathrm{~L} / \mathrm{min})$ \\
\hline
\end{tabular}




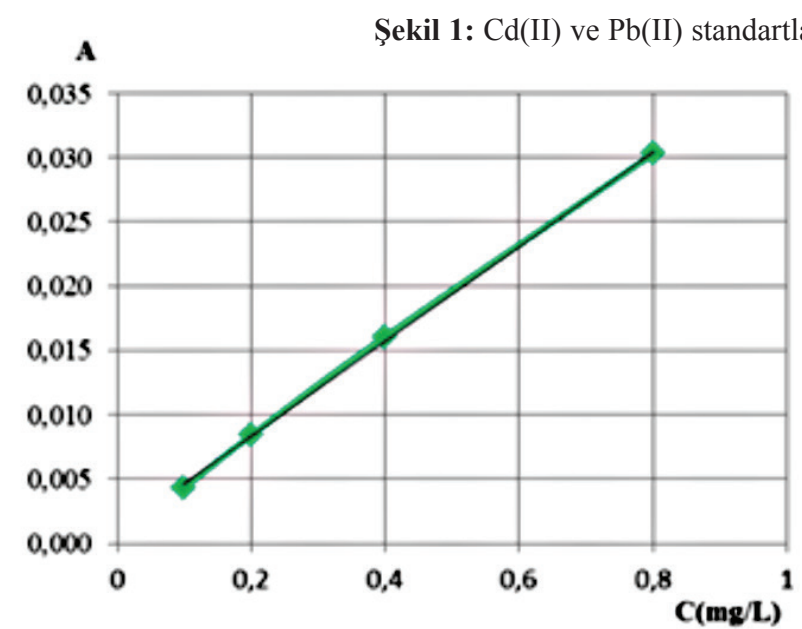

$\mathrm{Abs}=0,0369652 \mathrm{conc}+0,000913043(\mathrm{Cd}$ için $)$ $\mathrm{R}=0,9996$

Tablo 3: Satışa sunulan bazı bitkisel çay örneklerinin kurşun ve kadmiyum konsantrasyonlar1

\begin{tabular}{|c|c|c|c|c|}
\hline \multirow{2}{*}{$\begin{array}{l}\text { Bitkisel çay } \\
\text { numuneleri }\end{array}$} & $\begin{array}{l}\mathrm{Cd}(\mathrm{II}) \\
(\mathrm{ppm})\end{array}$ & $\mathrm{Pb}(\mathrm{II})(\mathrm{ppm})$ & $\begin{array}{l}\mathrm{Cd}(\mathrm{II}) \\
(\mathrm{ppm})\end{array}$ & $\begin{array}{l}\mathrm{Pb}(\mathrm{II}) \\
(\mathrm{ppm})\end{array}$ \\
\hline & \multicolumn{2}{|c|}{$\begin{array}{c}\text { Mikrodalga } \\
\text { çözünürleştirme }\end{array}$} & \multicolumn{2}{|c|}{ Yaş Yakma } \\
\hline Kekik(I) & 0,166 & 1,765 & 0,170 & 1,810 \\
\hline Kekik(II) & 0,177 & 1,728 & 0,179 & 1,720 \\
\hline Adaçayı(I) & 0,156 & 1,618 & 0,159 & 1,600 \\
\hline Adaçayı(II) & 0,155 & 1,691 & 0,150 & 1,700 \\
\hline Biberiye(I) & 0,131 & 0,958 & 0,150 & 0,900 \\
\hline Biberiye(II) & 0,136 & 0,110 & 0,135 & 0,289 \\
\hline Rezene(I) & 0,138 & 0,188 & 0,096 & 0,347 \\
\hline Rezene(II) & 0,137 & 0,184 & 0,113 & 0,259 \\
\hline Sar1 kantaron(I) & 0,186 & 1,655 & 0,111 & 1,289 \\
\hline Sarı kantaron(II) & 0,189 & 1,618 & 0,122 & 1,253 \\
\hline Ihlamur(I) & 0,156 & 1,728 & 0,132 & 1,249 \\
\hline Ihlamur(II) & 0,165 & 1,838 & 0,096 & 1,468 \\
\hline Nane(I) & 0,084 & 0,373 & 0,094 & 0,373 \\
\hline Nane(II) & 0,031 & 0,515 & 0,094 & 0,515 \\
\hline Papatya çayı(I) & 0,128 & 0,387 & 0,066 & 0,387 \\
\hline Papatya çayı(II) & 0,160 & 0,447 & 0,067 & 0,447 \\
\hline Yeşilçay(I) & 0,120 & 0,226 & 0,040 & 0,226 \\
\hline Yeşilçay(II) & 0,149 & 0,258 & 0,055 & 0,258 \\
\hline Yaban mersini(I) & 0,151 & 1,765 & 0,048 & 1,338 \\
\hline Yaban mersini(II) & 0,015 & 1,765 & 0,055 & 1,590 \\
\hline $\mathrm{X}$ (Ortalama) & 0,14 & 1,04 & 0,11 & 0,95 \\
\hline Standart Sapma & 0,05 & 0,72 & 0,04 & 0,60 \\
\hline En küçük değer & 0,02 & 0,11 & 0,04 & 0,23 \\
\hline En büyük değer & 0,19 & 1,84 & 0,18 & 1,81 \\
\hline
\end{tabular}

\section{BULGULAR}

\section{Standart Çözelti Hazırlanması}

Tayini yapılacak olan Titrisol Merck CertiPUR 1.19776.0100 Pb 1000mg/L ve Titrisol Merck CertiPUR $1.19777 .0100 \mathrm{Cd} 1000 \mathrm{mg} / \mathrm{L}$ stok standart çözeltileri kullanılmıştır.

\section{Kalibrasyon Eğrisinin Çizilmesi}

Kurşun ve kadmiyum için hazırlanan stok ve standart çözeltiler $0,005 \mathrm{mg} / \mathrm{L} ; 0,010 \mathrm{mg} / \mathrm{L} ; 0,015 \mathrm{mg} / \mathrm{L} ; 0,020$ $\mathrm{mg} / \mathrm{L}$ ve $0,025 \mathrm{mg} / \mathrm{L}$ konsantrasyonlarda hazırlanmış ve 3 'er okuma yapılarak konsantrasyon değerlerine karşılık gelen absorbans değerleri arasında grafik çizilmiştir. En küçük kareler yöntemine göre çizilen regresyon doğru denklemi, korelasyon katsayısı, eğim ve kesim noktası değerleri hesaplanmıştır. Doğrusallık çalışmasına ait verilerden korelasyon katsayısı kadmiyum için $\mathrm{r}=0,9996$, kesim noktası $\mathrm{b}=0,00091$ ve eğim değeri $\mathrm{m}=0,0370$; kurşun için $\mathrm{r}=0,9999$, kesim noktası $\mathrm{b}=0,0004$ ve eğim değeri $\mathrm{m}=0,0014$ olarak bulunmuştur (Şekil 1). Verilerin regresyon doğrusundan sapmasının (Kesim noktası /eğim*100) değeri kadmiyum için 2,4; kurşun için 2,8 olarak bulunmuştur. Elde edilen veriler metodun lineer ve doğrusal bir ilişkide olduğunu göstermiştir. Konsantrasyona karş1 absorbans değerleri grafiğe geçirildiğinde elde edilen doğru denklemleri sırasıyla $\mathrm{Cd}$ (II) için; $\mathrm{y}=0,0370 \mathrm{x}+0,00091$ ve $\mathrm{Pb}$ (II) için; $\mathrm{y}=0,0014 \mathrm{x}+0,0004$ olarak bulunmuştur. Seyreltmelerde $\% 0,5$ lik $\mathrm{HNO}_{3}$ kullanılmıştır.

\section{Çalışma Yöntemi:}

Çaylar iki farklı örnek hazırlama yöntemi kullanılarak analize hazır hale getirilmiştir. Uygulanan ilk yöntemde yaş yakma tekniği kullanılmıştır. Bunun için tartılan örnek der. 
Şekil 2: Kurşun ve kadmiyum ekstraksiyonun tamamlanması için gerekli süre

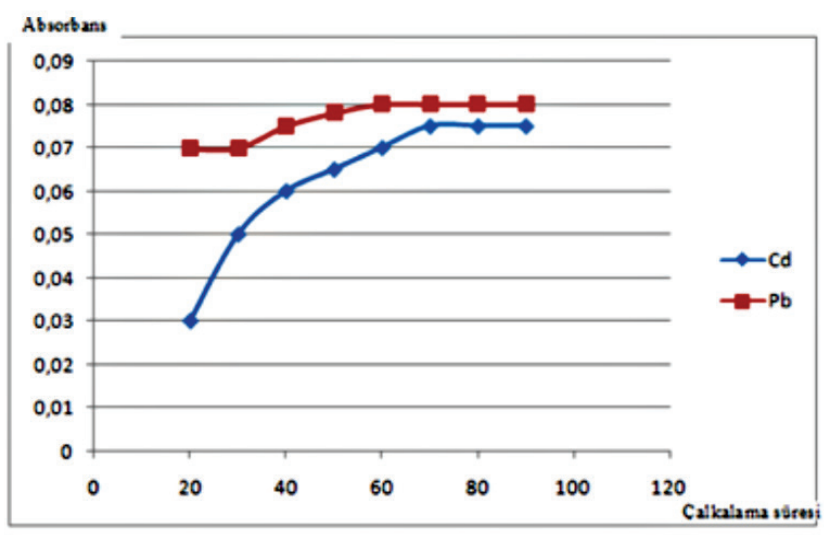

$\mathrm{HNO}_{3}$ ve der. $\mathrm{HClO}_{4}$ eklenerek kaynatılmış,ikinci yöntemde ise mikrodalga çözünürleştirme yöntemi kullanılmıştır. Parçalanmış kalıntı ultra saf su ile çözülerek filtre kullanılarak süzülmüş ve son hacim ultra saf su ile $100,0 \mathrm{ml}$ ye tamamlanmıştır.

Her iki yöntemde de çözünürleştirme işleminde kullanılan asitlerden dolayı hazırlanan çay numuneleri seyreltilerek kurşun ve kadmiyum için atomik absorbsiyon spektrofotometresi ile doğrudan enjeksiyon yöntemi ile çalışılmış ancak tekrarlanabilir sonuçlar elde edilememiştir. $\mathrm{Bu}$ nedenle bu etkileri giderebilmek için ekstraksiyon yöntemi uygulanmıştır. Ortam pH'1, kompleksleşme madde ve organik faz ekstraksiyonunda önemli olduğundan çözücü olarak metil izobutilketon ve kompleksleleşme ajanı olarak amonyum pirrolidin ditiyokarbamat kullanılmıştır (14).Çalışmada kadmiyum ve kurşun elementlerinin $\% 95$ oranında $\mathrm{pH}=3-6$ aralığında organik faza geçtiği bilindiğinden $\mathrm{pH}$ ayarlaması yapılmıştır ve $\mathrm{Pb}$ (II) ve $\mathrm{Cd}(\mathrm{II})$ nin kompleksinin sulu fazdan organik faza alımı sağlanmıştır. Ekstraksiyonun 70 dakika sonra tamamlandığı görülmüştür (Şekil 2).

İki yöntemle yapılan analizler sonucunda ortalamalar arasındaki farkın anlamlı olup olmadığına karar verirken $t$ istatistiği kullanılmıştır. Buna göre mikrodalga parçalama çözünürleştirmeyle elde edilen örneklerle yapılan analizlerin yaş külleme ile yapılan analizlere göre elde edilen sonuçlar arasındaki farkın \%5 seviyesinde anlamlı olmadı $\breve{g} 1$ görülmüştür. Çalışmada kullanılan bitki örneklerinde kadmiyum ve kurşun olmak üzere iki ağır metal analizi yapılmıştır ve araştırmanın materyalini oluşturan bitki örneklerinde, ağır metallerin belirtilen sınır değerlerinden daha fazla olmadığı tespit edilmiştir.
Şekil 3: Yaş külleme ve mikrodalga çözünürleştirme uygulanan çay örneklerinin kurşun ve kadmiyum değerleri

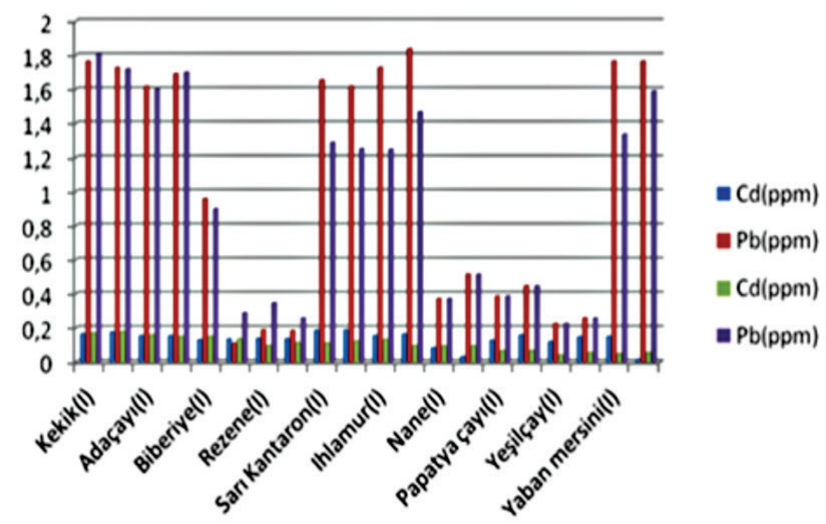

\section{TARTIŞMA VE SONUÇ}

Bitki çaylarının sağlık açısından birçok faydası olduğu bilinmesine rağmen bunların yanlış ya da fazla kullanımı veya üretiminin denetimsizliğinden dolayı birtakım kontaminasyonlara maruz kalması durumunda insan yaşamında önemli bir tehdit unsurudur. Bu maruziyetlerin önemli bir kısmını ağır metaller oluşturmaktadır. Çeşitli kaynaklardan ortaya çıkan pek çok zararlı madde ile bitkilerin yaşama ortamı kirlenmektedir. Endüstrinin gelişmesi ve giderek artan trafik, pestisidler, sanayi ve evsel atıklar gibi faktörler ağır metal kirliliğini arttırmaktadır.

Ağır metal birikimi ve sebep olduğu sağlık sorunlarını önlemek için bitkinin toplanması, üretim, ambalajlama, muhafaza, depolama gibi aşamalarda ağır metal bulaşmasının önlenmesi önemlidir. Halkın bilinçsiz ve kontrolsüzce bunları kullandığı düşünülürse bu alanda hukuki düzenlemelerin ve denetlemelerin yapılması son derece önemlidir.

Çalışmada kullanılan bitki örnekleri yaş külleme ve mikrodalga çözünürleştirme ön işlemleri uygulanarak analize hazırlanmış ve ağır metal içerikleri atomik absorpsiyon spektrofotometresi kullanılarak tayin edilmiş ve sonuçları Tablo 1 ve Tablo 3'de gösterilmiştir. Sonuçlar incelendiğinde Gıda ve Kontrol Genel Müdürlüğü yönetmeliğine göre araştırmanın materyalini oluşturan bitki örneklerinde, kadmiyum ve kurşun metallerin belirtilen sınır değerleri arasında olduğu görülmüştür. Sonuç olarak, çeşitli hastalıkların tedavisinde kullanılan tıbbi bitkilerin bilinçli olarak tüketilmesi, analizi yapılmış, içeriği belli olan bitki türlerinin alternatif tıpta kullanılması yaşanabilecek tehlikeli sonuçları engelleyecektir. 


\section{BILGILENDIRME}

Bu çalışma Marmara Üniversitesi Bilimsel Araştırma Projeleri Komisyonu Başkanlığı tarafından desteklenmiştir.

Proje No: SAĞ-A-031110-0256.

\section{Determination of heavy metals in herbal teas marketed in İstanbul}

\section{SUMMARY}

Herbal teas are being used pretty much in Turkey. Besides having a lot of beneficial speciality, teas carry heavy metals in their structure and heavy metal pollution increase with environmental pollution. In this study; sage, rosemary, St. John'swort, linden, mint, thyme, chamomile, fennel, green tea, blueberries were used and lead and cadmium metals in this teas which were bought from herbalist, have been researched with Atomic Absorption Spectrophotometer. According to the results, cadmium and lead concentrations in all dried samples have been found in the limits of Turkish Food Codex.

Key words: Herbal tea, heavy metal, atomic absorption, cadmium(II), lead(II)

\section{KAYNAKLAR}

1. Baytop T. Türkiye'de Bitkiler İle Tedavi (Geçmişte ve Bugün). Nobel Tip Kitabevleri, İstanbul. 1999.

2. Gürkan E. Bitkisel Tedavi. Marmara Üniversitesi Eczacılık Fakültesi Farmakognozi Anabilim Dal1, İstanbul. 2007.

3. Kaya DB. Piyasada Satışa Sunulan Bazı Bitkisel Çayların Mikrobiyolojik Kalitesi. Ankara Üniversitesi Fen Bilimleri Enstitüsü Gıda Mühendisliği Anabilim Dalı, Yüksek Lisans Tezi, Ankara. 2006.

4. Algan G. Konya Yöresi Sütlerinde Bazı Ağır Metallerin İncelenmesi. Selçuk Üniversitesi Sağlık Bilimleri Enstitüsü Besin Hijyeni ve Teknoloji Anabilim Dalı, Yüksek Lisans Tezi, Konya. 2002.

5. Parıldar S. Aktarlarda Satılan Antidiyabetik Etkili Droglar Üzerinde Araştırmalar. İstanbul Üniversitesi Sağlık Bilimleri Enstitüsü Farmakognozi Anabilim Dalı, Yüksek Lisans Tezi, İstanbul. 2001.

6. Özcan M. Mineral contents of someplantsused as condiments in Turkey. Food Chem 2004;84: 437-40.

7. Ergün N. ve ark. Amanoslarda yetişen bazı bitki türlerinde ağır metal birikimi ve mineral içerik üzerine çalışma. BİBAD 2010;3: 121-7.
8. Leblebici S, Bahtiyar SD, Özyurt MS. Kütahya aktarlarında satılan bazı bitkilerin ağır metal içeriklerinin incelenmesi. DPÜ Fen Bilimleri Enstitüsü Dergisi 2012;29: 1-6.

9. Bedir N. Açık ve Paket Çaylarda Bulunan Ağır Metallerin ICP-OES ile Analizleri. Sakarya Üniversitesi, Fen Bilimleri Enstitüsü Kimya Bilim Dalı, Yüksek Lisans Tezi, Sakarya. 2010.

10. Öktüren Asri F, Sönmez S, Çıtak S. Kadmiyumun çevre ve insan sağlığı üzerine etkileri. DERİM 2007;24: 32-9.

11. Kahvecioğlu Ö, Kartal G, Güven, Timur S. Metallerin Çevresel Etkileri - I. http://www.metalurji.org.tr/dergi/ dergi136/d136_4753.pdf [Erişim Tarihi 23.04.2011]

12. Baş L, Demet Ö. Çevresel toksikoloji yönünden bazı ağır metaller. Ekoloji 1992;5: 42-6.

13. Topçuoğlu. B. Kentsel katı atık kompostu ve arıtma çamurunda ağır metallerin bitkiler ve çevre üzerinde potansiyel etkileri ve kirletici limitleri. DERİM 2002;19: 38-49.

14. Skoog DA, Holler FJ, Nieman TA. Enstrümantel Analiz, Ed: Kılıç E, Köseoğlu F, Yılmaz H. Bilim Yayıncılık. 1971, pp 193-227. 